\title{
Composition and Nutrients Depletion after Cooking Three Pigmented Varieties of Whole Grain Rice from Côte d'Ivoire
}

\author{
Rebecca Rachel Epse Yao Assa, Tiatou Souho, Soronikpoho Soro
}

\section{ABSTRACT}

Rice (Oryza sativa) is the most consumed food in the world and represents an important diet element in Côte d'Ivoire. Composition data on rice varieties produced and consumed in Côte d'Ivoire are not available rendering it difficult to evaluate their nutritional importance in consumers. The purpose of the present study was to determine whole grains' biochemical composition of three local pigmented varieties and evaluate the effect of boiling on this composition. The moisture, ashes, carbohydrates, lipids, proteins and polyphenols rates were determined using standard methods on raw and cooked whole grain samples from studied varieties. Results showed that the nutrient characteristics of raw rice are superior to those of cooked rice. The boiling treatment used to cook the rice induced starch and fibre hydrolysis into simple carbohydrates, and reduced rates of all nutrients. This first study focused on Côte d'Ivoire locally produced rice varieties open the road for further investigations that will nourish the food composition tables for the main types of raw and cooked foods consumed in West Africa.

Keywords: Cooked rice, Côte d'Ivoire, Nutritional characterization, Oryza sativa, Whole grain rice.

Published Online: October 30, 2020

ISSN: 2684-5199

DOI : $10.24018 /$ ejbio.2020.1.5.57

Rebecca Rachel Epse Yao Assa UFR Biosciences, Université Félix Houphouët-Boigny, Abidjan, Côte d'Ivoire.

(e-mail: assa_rebecca ${ }^{@}$ yahoo.fr)

Tiatou Souho *

Laboratoire de biochimie des Aliments et Nutrition, Faculté des Sciences et Techniques, Université de Kara, Kara, Togo.

(e-mail: souhotia@yahoo.fr)

Soronikpoho Soro

UFR Biosciences, Université Félix Houphouët-Boigny, Abidjan, Côte d'Ivoire.

(e-mail: soronik@yahoo.com)

*Corresponding Author

\section{INTRODUCTION}

In the particular context of the nutritional double burden observed in Subsaharan African countries, it is necessary to set up and continuously update food composition tables/data bases that could serve as tools to evaluate effective nutrients intake in the population and provide appropriate recommendations for healthy nutrition [1], [2]. One of the challenges in building such databases is to cover nutrient composition of all the available foods or at least, the most consumed foods in the region and determine nutrients retention factors at least for the most used processing or cooking methods.

In West Africa, a regional food composition table was set up but more efforts are still needed in capacity building and some foods are still needed to be analyzed in order to complete the table [3], [4]. In addition, there are some specificities due to some food varieties produced in climatic particularities in some West African countries as well as some underestimated edible species. Rice (Oryza sativa) occupies an important place in West African countries food systems due to its accessibility and potentials for transformation into several foods [5]. It was introduced in Côte d'Ivoire from Asia in the 15th century and evolved during centuries to present some specific features in the country [6].

In Côte d'Ivoire, rice is consumed in several forms according to household resources and cooking methods. Among the available rice in markets, the whole grain rice is highly recommended by health care providers because of its high rates of proteins, vitamins and minerals present in germs and bran that are removed in the refined white rice [7], [8]. Moreover, the whole rice presents a relatively low glycemic index in comparison to refined white rice making it a preferred cereal for patients suffering from diabetes [9, 10]. Composition data and processing nutrients retention factors in locally produced whole grain rice are missing despite their high importance in Ivoirians' nutrition. It is therefore of great importance to determine the composition of locally produced rice and estimate the nutrients retention factors following rice cooking in order to contribute to the developing West African food composition database.

The present study was designed with the purpose of performing a comparative study between raw and cooked whole grain rice of three different varieties produced in Côte d'Ivoire and distinguishable based on grain colour. The study also intended to determine the influence of the commonly used cooking method in Côte d'Ivoire on main nutrients present in rice. 


\section{MATERIAL AND METHODS}

\section{A. Rice Varieties}

The study was focused on three commonly consumed rice varieties distinguished by their colours (Beige, brown, and black). The sampled rice was produced locally and sampled in duplicate from two rice sellers in Abidjan and Bongouanou. For each variety, $2 \mathrm{~kg}$ were sampled, cleaned, and split into two parts for biochemical analyses of raw and cooked rice.

\section{B. Biochemical Analysis}

Each sample was split into two parts. The first part was kept for biochemical analysis of the raw rice whereas the second part was cooked before analyses. The cooking process was performed by boiling rice in two-fold volumes of rice for 25 minutes.

The moisture and rates of ashes and proteins were determined using the AOAC methods of analyses [11]. Total starch and fibre rates were obtained by spectrophotometric approaches [12]. The level of lipids in the rice grains and cooked rice was determined using French standards procedures [13]. Polyphenols were analysed by the folinciocalteu reagent method and polyphenols rates expressed in $\mathrm{mg} / 100 \mathrm{~g}$ of the Gallic acid equivalent (GAE) [14].The whole carbohydrates level was estimated using the differential method [15]. The Atwater formula was used to calculate the whole energy value [16].

\section{Data Analysis}

All the obtained data were entered in an excel data sheet and analyzed using Statistica 7.1. All analyses and tests were performed with a significance level set at $\mathrm{p}<0.05$.
Apparent retention factors (ARF) were calculated using the following formula: $\mathrm{ARF}=100 \times \mathrm{Nc} / \mathrm{Nr}$.

$\mathrm{Nc}=$ nutrient content per $\mathrm{g}$ of cooked whole rice

$\mathrm{Nr}=$ nutrient content per $\mathrm{g}$ of raw whole rice.

\section{RESUlTS}

Three locally produced rice varieties were sampled in duplicate and subjected to biochemical analyses before and after cooking.

\section{A. Moisture and ashes level}

Three locally Raw rice varieties presented moisture rates ranging from 9.47 to $11.27 \%$ whereas boiled rice showed significantly higher moisture rates of 70.12 to $71.10 \%$ (Fig. 1). Mineral nutrients in rice samples were evaluated as a whole in the rate of ashes. In raw rice samples this rate ranged from 1.24 to $1.40 \%$. After cooking rice samples by boiling in water, the ashes content dropped significantly to a range from 0.55 to $0.72 \%$ (Table 1 ).

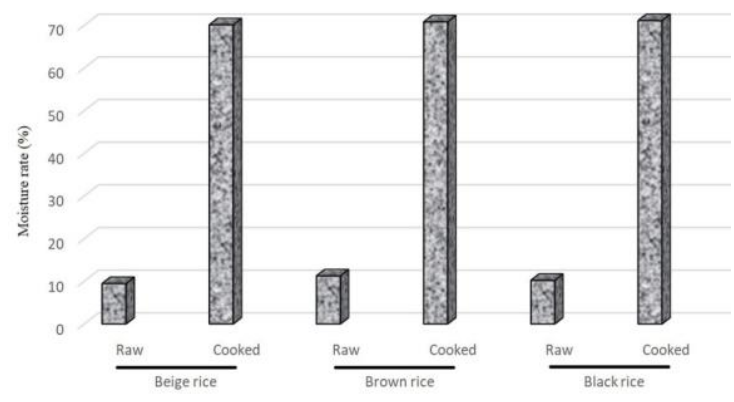

Fig. 1. Moisture rates in raw and cooked rice.

TABLE1: BIOCHEMICAL COMPOSITION OF RAW AND COOKED RICE SAMPLES

\begin{tabular}{|c|c|c|c|c|c|c|}
\hline \multirow[b]{2}{*}{ Compound } & \multicolumn{2}{|c|}{ Beige rice } & \multicolumn{2}{|c|}{ Brown rice } & \multicolumn{2}{|c|}{ Black rice } \\
\hline & Raw & Cooked & Raw & Cooked & Raw & Cooked \\
\hline Ashes (\%) & $1.24 \pm 0.11$ & $0.55 \pm 0.11$ & $1.42 \pm 0.13$ & $0.69 \pm 0.13$ & $1.31 \pm 0.20$ & $0.72 \pm 0.33$ \\
\hline Fibres (\%) & $6.11 \pm 0.33$ & $2.30 \pm 0.23$ & $5.21 \pm 0.33$ & $2.03 \pm 0.11^{\mathrm{d}}$ & $5.50 \pm 0.77$ & $2.04 \pm 0.80$ \\
\hline Carbohydrates (\%) & $73.9 \pm 0.9$ & $26.20 \pm 0.53$ & $73.85 \pm 0.98$ & $27.52 \pm 0.9$ & $74.87 \pm 0.95$ & $30.17 \pm 0.94$ \\
\hline Starch $(\%)$ & $70.81 \pm 0.98$ & $23.03 \pm 0.91$ & $71.51 \pm 0.91$ & $24.06 \pm 0.9$ & $70.21 \pm 0.93$ & $27.11 \pm 0.88$ \\
\hline Protéins (\%) & $5.92 \pm 0.93$ & $3.8 \pm 0.90$ & $6.02 \pm 0.53$ & $2.60 \pm 0.83$ & $8.5 \pm 0.90$ & $3.50 \pm 0.11$ \\
\hline Fat $(\%)$ & $1.35 \pm 0.33$ & $0.56 \pm 0.11$ & $1.35 \pm 0.15$ & $0.75 \pm 0.13$ & $1.65 \pm 0.93$ & $0.80 \pm 0.03$ \\
\hline $\begin{array}{l}\text { Polyphenols (mg } \\
\text { GAE /100g) }\end{array}$ & $50.01 \pm 0.91$ & $30.22 \pm 0.6$ & $56.12 \pm 0.95$ & $32.31 \pm 0.80$ & $81.04 \pm 0.96$ & $41.25 \pm 0.60$ \\
\hline $\begin{array}{l}\text { Energetic value } \\
(\mathrm{Kcal} / 100 \mathrm{~g})\end{array}$ & $331.5 \pm 0.13$ & $116.36 \pm 0.36$ & $331.48 \pm 0.21$ & $121.13 \pm 0.03$ & $348.33 \pm 0.18$ & $129.28 \pm 0.05$ \\
\hline
\end{tabular}

\section{B. Composition in macronutrients}

The evaluation of the macronutrients content revealed carbohydrates as the main components in both raw and boiled rice samples. Total carbohydrates represented a fraction of 73.21 to $74.51 \%$ in raw rice samples. Boiling this rice induces a decrease in total carbohydrates of almost a tierce in the three varieties. The black rice variety presented the highest rate of total carbohydrates $(30.17 \%)$ after cooking. The major carbohydrate was starch which was found to be present in proportions comprised between 70.21 and $71.21 \%$ in raw rice, and 23.03 to 27.11 in cooked rice. The fibre fraction accounted from 5.21 to $6.11 \%$ in raw rice and 2.03 to 2.30 in boiled rice. The highest rate of fibre was recorded in rice coloured in beige (Table 1).
Like carbohydrates, cooking rice also induced a decrease in protein content in rice samples. In fact, the protein level dropped from a range from 5.92 to $8.5 \%$ in raw rice to a range from 2.60 to 3.80 after cooking. The black rice presented the highest content in proteins (Table 1).

As presented in Table 1, lipids were found to be present in raw rice with rates of 1.35 to $1.65 \%$. These rates drop to 0.56 to $0.80 \%$ after cooking rice samples (Table 2 ).

Based in the content in macronutrients, the energetic value of sampled rice varieties was estimated using the Atwater method. The energetic value was found to range from 331.48 to $348.33 \mathrm{kcal} / 100 \mathrm{~g}$ in raw rice. After cooking, the energetic value ranged from 116.36 to $129.28 \mathrm{kcal} / 100 \mathrm{~g}$ (Tables 1 and 2). 
TABLE 2: APPARENT RETENTION FACTORS OF STUDIED NUTRIENTS

\begin{tabular}{lccc}
\hline \hline Compound & Beige rice & Brown rice & Black rice \\
\hline Ashes & 44.35 & 48.59 & 54.96 \\
Fibres & 35.45 & 37.26 & 40.30 \\
Carbohydrates & 32.52 & 33.65 & 38.61 \\
Starch & 37.64 & 38.96 & 36.91 \\
Protéins & 64.19 & 43.19 & 41.18 \\
Fat & 41.48 & 55.56 & 48.48 \\
Polyphenols & 60.43 & 57.57 & 50.90 \\
Energetic value & 35.10 & 36.54 & 37.11 \\
\hline \hline
\end{tabular}

All apparent retention factors are expressed in percentage.

\section{Polyphenols content}

Due to their importance as antioxidants, polyphenols were also analysed in this rice composition study. Results show that these components are present in sampled rice varieties at ranges comprised between 50.01 and $81.04 \mathrm{mgGAE} / 100 \mathrm{~g}$ in raw rice. After boiling the rice, polyphenols were recorded at rates ranging from 30.22 to $41.25 \mathrm{mgGAE} / 100 \mathrm{~g}$ (Tables 1 and 2).

\section{DISCUSSION}

With the aim of providing more data on the composition of locally produced foods for a better nutritional valorisation, the present study was conducted on three coloured rice varieties produced in Côte d'Ivoire. Rice samples were collected from markets in order to evaluate the composition of effectively consumed rice in households. Results show that these locally produced rice varieties present high nutritional values in comparison to other widely consumed rice.

Among physicochemical parameters, the moisture content is a key element that determines rice susceptibity to pests, fungi and microbes [17], [18]. These contaminants require high water activity to proliferate. It is therefore necessary to dry grains till low moisture content for better storage, however, too low moisture content can lead to fissures [19]. The three studied rice samples presented moisture rates lower than $10 \%$. These values highlight a potential for long period storage. In addition whole grains absorb less amount of water during storage in comparison to polished rice. It is important to notice that during rice boiling, grains absorb water and swell at rates variable according to cooking time and variety [20].

At biochemical composition level, the three studied rice varieties are quiet similar with high levels of proteins, ashes, and fibres. The black rice revealed to be a relatively higher quality variety with highest values of energy, total carbohydrates, proteins, ashes, and polyphenols content. This variety should be highly promoted as it could be with great added value in the eradication of malnutrition. The three studied rice varieties interestingly showed high levels of fibre $(5.21$ to $6.11 \%)$ in comparison to other varieties produced elsewhere [21]. This finding should encourage the promotion of these three locally produced varieties in people suffering from special conditions that require high levels of fibre in their food for a better digestion and metabolism [22].

Another added value observed in the studied rice is their content in polyphenols. Deeper investigations are required to identify the specific polyphenolic compounds but there are several studies reporting the good effect of rice polyphenols [23], [24]. A part from the potential of rice polyphenols as natural antioxidants with beneficial effects on consumers, these compounds present a particular importance in different rice processing technologies. In fact, polyphenols were proven to affect water-starch interactions and then participate in the pasting processes [25]. The use of external polyphenols in rice starch processing was also encourage as it accelerate gelatinization and changes the structural and physicochemical properties of rice starch at room temperature under high pressure [26].

As for any other foods, cooking rice by boiling it induced the reduction in the rates of all nutrients. These reductions in nutrients rates lead to a decrease in the total equivalent energy. Apparent retention factors were determined and reported in Table 2. In the studied rice samples, around 63 $\%$ of the total energy value was lost showing that the cooking process alters a huge amount of macronutrients. Alternative processes are needed allow people in Côte d'Ivoire to profit from all nutrients present in the rice they eat. Given that most the foods in West African countries are cooked by long boiling processes, there should be a regional programme to propose solutions to malnutrition that take into account the cooking methods.

The highest rates reductions are recorded for total carbohydrates, starch, fibres and mineral fraction (ashes). Polymeric carbohydrates such as starch and cellulose in fibres undergo hydrolytic reactions that generate simple and easily digestible molecules. This hydrolytic phenomenon induces an increase in carbohydrates digestibility and the glycemic index of cooked rice [27]. This result was also recorded in other studies and shows that rice cooking processes should be seriously monitored especially in individuals suffering from diabetes [10]. In addition, the starch is mobilized with water for gelatinization during the cooking process allowing all the rice varieties to swell.

The loss in rice mineral compounds can be attributed to both rice washing before preparation and the boiling process. However, despite this loss in the mineral fraction, the cooking process may have increased the bio accessibility of some minerals such as $\mathrm{Mg}, \mathrm{Fe}$, and $\mathrm{Ca}$ [28]. Anyway, the loss in ashes is significantly high. It is therefore necessary to pay a particular attention to people whose alimentation is mainly based on rice. Supplementations in minerals and vitamins could be necessary for some vulnerable individuals such as children.

\section{CONCLUSION}

The present study provides important composition data on three locally produced rice varieties in Côte d'Ivoire. These three coloured rice varieties present high nutritional qualities even if the cooking process used in the country lead to significant nutrients losses. Further investigations are needed to identify and quantify the level of vitamins and minerals in these rice varieties. Finally, nutritional recommendations should provide more advices on cooking processes that preserve rice from nutrients loss. 


\section{REFERENCES}

[1] Saito A, Okada E, Matsumoto M, Takimoto H. Impact of updated standard tables of food composition on nutrient intakes in Japan. Journal of Food Composition and Analysis. 2019; 79:5-11.

[2] van Heerden SM, Schönfeldt HC. The need for food composition tables for southern Africa. Journal of Food Composition and Analysis. 2004;17(3):531-7.

[3] Stadlmayr B, Charrondière UR, Burlingame B. Development of a regional food composition table for West Africa1The views expressed in this information product are those of the author(s) and do not necessarily reflect the views of FAO.1. Food Chemistry. 2013;140(3):443-6

[4] Schönfeldt HC, Hall N. Capacity building in food composition for Africa. Food Chemistry. 2013;140(3):513-9.

[5] Abera BB, Terefe B, Baye K, Covic N. Rice Contribution to Food and Nutrition Security and Leveraging Opportunities for Sustainability, Nutrition and Health Outcomes. In: Ferranti P, Berry EM, Anderson JR, editors. Encyclopedia of Food Security and Sustainability. Oxford: Elsevier; 2019. p. 257-63.

[6] Jean-Pierre D. Bilan d'une expérience rizicole en Côte d'Ivoire : logique des développeurs et réalités des développés. Paris, France: CIFACE; 1985.

[7] Somaratne GM, Prasantha BDR, Dunuwila GR, Chandrasekara A, Wijesinghe DGNG, Gunasekara DCS. Effect of polishing on glycemic index and antioxidant properties of red and white basmati rice. Food Chemistry. 2017;237:716-23.

[8] Goyon A, Mestres C. Le riz: bénéfices et risques pour la santé. Cahiers de Nutrition et de Diététique. 2017;52(4):202-9.

[9] Kongkachuichai R, Charoensiri R, Meekhruerod A, Kettawan A Effect of processing conditions on bioactive compounds and glycemic index of the selected landrace rice variety in pre-diabetes. Journal of Cereal Science. 2020; 94:102994.

[10] Chang UJ, Hong YH, Jung EY, Suh HJ. Chapter 27 - Rice and the Glycemic Index. In: Watson RR, Preedy VR, Zibadi S, editors. Whea and Rice in Disease Prevention and Health. San Diego: Academic Press; 2014. p. 357-63.

[11] AOAC. AOAC Official Methods of Analysis. 15th Edition. Arlington, USA: Association of Official Analytical Chemists; 1990.

[12] Jarvis CE, Walker JRL. Simultaneous, rapid, spectrophotometric determination of total starch, amylose and amylopectin. Journal of the Science of Food and Agriculture. 1993;63(1):53-7.

[13] AFNOR. Recueil de Norme Française, corps gras, grains oléagineux, produit dérivé. Paris, France: AFNOR; 1986.

[14] Singleton VL, Orthofer R, Lamuela-Raventós RM. [14] Analysis of total phenols and other oxidation substrates and antioxidants by means of folin-ciocalteu reagent. Methods in Enzymology. 299: Academic Press; 1999. p. 152-78.

[15] FAO. Food energy-methods of analysis and conversion factors: Report of a Technical Workshop, Rome, 3-6 December 2002. Roma, Italy: 2003

[16] Widdowson EM. Assessment of the Energy Value of Human Foods. Proceedings of the Nutrition Society. 2007;14(2):142-54.

[17] Abdullah N, Nawawi A, Othman I. Fungal spoilage of starch-based foods in relation to its water activity (aw). Journal of Stored Products Research. 2000;36(1):47-54.

[18] Ozbekova Z, Kulmyrzaev A. Study of moisture content and water activity of rice using fluorescence spectroscopy and multivariate analysis. Spectrochimica Acta Part A: Molecular and Biomolecular Spectroscopy. 2019; 223:117357.

[19] Hashemi Zadeh Haghighi SJ, Shimizu N. Investigation of Fissure Formation During the Drying and Post Drying of Japonica Aromatic Rice. International Journal of Agriculture and Biology. 2008;10.

[20] Vidal V, Pons B, Brunnschweiler J, Handschin S, Rouau X, Mestres C. Cooking Behavior of Rice in Relation to Kernel Physicochemica and Structural Properties. Journal of agricultural and food chemistry. 2007; 55:336-46.

[21] Bhat FM, Riar CS. Effect of composition, granular morphology and crystalline structure on the pasting, textural, thermal and sensory characteristics of traditional rice cultivars. Food Chemistry. 2019; 280:303-9.

[22] Cheng H-H. Total dietary fiber content of polished, brown and bran types of Japonica and Indica rice in Taiwan: Resulting physiological effects of consumption. Nutrition Research. 1993;13(1):93-101.

[23] Khosravi A, Razavi SH. The role of bioconversion processes to enhance bioaccessibility of polyphenols in rice. Food Bioscience. 2020; 35:100605

[24] Callcott ET, Santhakumar AB, Luo J, Blanchard CL. Therapeutic potential of rice-derived polyphenols on obesity-related oxidative stress and inflammation. Journal of Applied Biomedicine. 2018;16(4):255-62.

[25] Han X, Zhang M, Zhang R, Huang L, Jia X, Huang F, et al Physicochemical interactions between rice starch and different polyphenols and structural characterization of their complexes. LWT. 2020; 125:109227.

[26] Du J, Yang Z, Xu X, Wang X, Du X. Effects of tea polyphenols on the structural and physicochemical properties of high-hydrostaticpressure-gelatinized rice starch. Food Hydrocolloids. 2019; 91:256 62.

[27] Wang S, Li P, Zhang T, Yu J, Wang S, Copeland L. In vitro starch digestibility of rice flour is not affected by method of cooking. LWT 2017; 84:536-43.

[28] Liu K, Zheng J, Wang X, Chen F. Effects of household cooking processes on mineral, vitamin $\mathrm{B}$, and phytic acid contents and minera bioaccessibility in rice. Food Chemistry. 2019; 280:59-64.

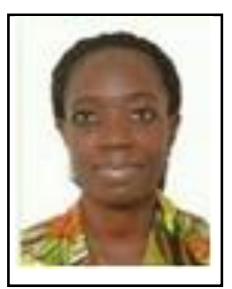

ASSA Rebecca Rachel Epse YAO is a Professor at Université Félix Houphouët-Boigny in Côte d'Ivoire where she obtained her $\mathrm{PhD}$ at the in the Laboratory of Biochemistry and Food Sciences. She is now responsible for teaching units of Biotechnologies, Beverage and water technologies. Her research focuses on three axes (Nutritional and sanitary characterization of foods, Valorisation of food byproducts and residues, and Food and nutritional security).

Dr ASSA is now working on collaborative projects with the Center for International Cooperation in Agricultural Research for Development (CIRAD). She is member of several scientific societies such as the Ivorian Society of Nutrition (SIN), the Research Network on Public Policies and Food Systems in West Africa (REPSAO). She is member of the Agricultural Gender Platform of FIRCA and Secretary General of the Association of Women Researchers of Côte d'Ivoire. She is in charge of Gender and External Relations at the Research, Development and Innovation Department of UFHB and works as the Coordinator of the Food Security and Nutrition Research Program (PTR SAN) of CAMES.

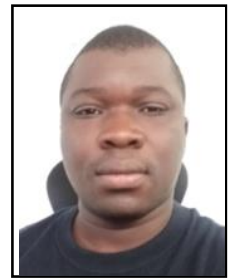

SOUHO Tiatou studied at Sidi Mohamed Ben Abdellah University, Morocco, where he received a Master's degree in Microbial Biotechnology (2010) and $\mathrm{a} \mathrm{PhD}$ in Microbiology and Molecular Biology (2015). He performed postdoctoral trainings at the Faculty of Medicine and Pharmacy of Fez, Morocco, and at Huazhong University of Science and Technology, China. He is interested in understanding nutritional and infectious agents' implications in human oncogenesis

Dr SOUHO Tiatou in now a Senior Lecturer at Université de Kara in Togo where he is responsible for educational units of Microbiology, Food chemistry and Biotechnologies. He is member of the Research Network on Public Policies and Food Systems in West Africa (REPSAO) and works also as the General Reporter of the Food Security and Nutrition Research Program (PTR SAN) of CAMES.

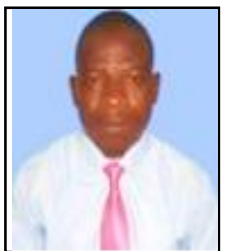

SORO Soronikpoho is a Senior Lecture at Université Félix Houphouët-Boigny working in the Laboratory of Biochemistry and Food Sciences. He graduated his $\mathrm{PhD}$ at the same university and his research activities are mainly focused on food processing technologies.

Among other achievements, Dr SORO Soronikpoho has developed several food formulations based on soy beans and yam to improve nutritional status in children. He also evaluates the biochemical composition of edible vegetal species for their potential to achieve food security. 